\title{
THE ROLE OF CD44 AND SOX-2 CANCER STEM CELL MARKERS IN THE DEVELOPMENT AND PROGRESSION OF MUCOEPIDERMOID CARCINOMA AND PRIMARY SQUAMOUS CELL CARCINOMA OF SALIVARY GLANDS
}

\author{
Naglaa M. Kamal *
}

\begin{abstract}
One of the greatest difficulties to reach a successful treatment of mucoepidermoid carcinoma (MEC) and primary squamous cell carcinoma (PSSC) of salivary glands is the resistance to different therapeutic procedures which advocate the existence of a subpopulation of cancer stem cell (CSC). In salivary gland tumors the hypothesis of cancer stem cell has not been fully understood.
\end{abstract}

Aim: To assess the expression of cancer stem cell markers CD44 and SOX2 in low and highgrades MEC and PSSC and to determine whether the expression of these markers can be used to predict tumor aggressiveness.

Materials and Methods: $4 \mu \mathrm{m}$ sections were prepared from paraffin-embedded blocks of 16 samples of MEC and 16 samples of PSSC of salivary glands (8 low-grade and 8 high-grade carcinomas for each of them). Staining of each specimen with hematoxylin and eosin, CD44 and SOX2 was done.

Results: All lesions of MEC and PSSC showed membranous CD44 and nuclear SOX2 expression. CD44 and SOX2 expression were significantly higher in high-grade tumors than in low-grade tumors. A strong positive correlation between CD44 and SOX2 expression was detected.

Conclusion: Cancer stem cells can be identified in MEC and PSSC using CD44 and SOX2 markers and may participate in tumor aggressiveness. The present study also suggests that patients with MEC and PSSC may benefit from therapies that comprise a combination of the two markers.

KEYWORDS: Mucoepidermoid carcinoma, primary squamous cell carcinoma, CD44, SOX2, immunohistochemistry

* Lecturer, Oral Pathology Department, Faculty of Oral and Dental Medicine, Ahram Canadian University, $6^{\text {th }}$ of October City, Giza Egypt. 


\section{INTRODUCTION}

Salivary gland malignancies are relatively rare tumors. ${ }^{1}$ Mucoepidermoid carcinoma (MEC) is considered one of the most prevalent malignant salivary gland neoplasms detected in the minor and major salivary glands. It affects children and adults.

MECs are classified histologically as low, intermediate and high grades. ${ }^{2}$ Treatment of MEC consists of surgical resection with or without adjuvant radiotherapy, depending on the tumor grade. Meanwhile, there are no effective treatment options for patients with locally invasive, recurrent, or metastatic neoplasm. ${ }^{3}$

The prognosis of this tumor relies mostly on the histological grade, as high-grade tumors are very aggressive, while the low-grade ones are less aggressive and usually have a more benign nature. Studying the pathobiology of this malignancy and the mechanism implicated in therapy resistance is very important to enhance the quality of life and the survival of patients with MEC. ${ }^{4}$

Primary squamous cell carcinoma (PSCC) is a malignant epithelial neoplasm which has an aggressive behavior and accounts for less than $1 \%$ of all neoplasms of the salivary glands.$^{5,6,7}$ It is crucial to restrain the diagnosis of PSCC to major salivary glands because it is impossible to verify whether the neoplasm originates from minor salivary glands themselves or from the nearby mucosa. ${ }^{89}$ PSSC may arise from a metaplastic salivary gland epithelium with a latency of 15-30 years. Ionizing radiation

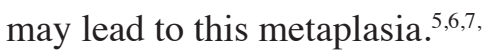

Treatment of PSSC consisted of surgical excision. Adjuvant radiotherapy or chemotherapy depends on the degree of tumor distribution. ${ }^{10,11}$

The most established theory for the etiopathogenesis of cancer is that the tumor begins as a solitary cell which has some features of that of the normal stem cells. ${ }^{12,13}$ This cancer stem cells (CSCs) have an important role in tumor progression, recurrence, therapeutic resistance and metastasis in many types of cancers as pancreatic cancer, breast cancer and head and neck cancer. So, identification and killing this CSCs could be an important goal of cancer therapy. ${ }^{14,15,16}$

Many studies characterized CSCs based on stem cell markers expression and correlated their expression with the clinical and histopathological features. Among the CSC markers are, CD133, CD24, CD44, SOX2, Oct4, Nanog and Bmi-1. ${ }^{17,18,19}$

Regarding salivary gland carcinomas, the role of stem cell markers is not fully investigated..$^{20}$

CD44 is a transmembrane glycoprotein which regulates the expression of certain genes responsible for cell behaviors. It can transduce microenvironmental cellular signals to cell nucleus or cell membrane-associated proteins. Previous studies suggested that CD44 is a cancer stem cell marker and is an important regulator of cancer stemness, which includes the ability of self-renewal, tumor initiation, and tumor metastasis. ${ }^{21,22,23}$

SOX2 is one of the members of the SOX family gene. It is a transcription factor that shares in several embryonic processes as sex determination and plays a functional role in maintaining the embryonic stem cells state. Under certain conditions, SOX2 can reprogram differentiated cells into pluripotent stem cells. ${ }^{24,25}$ Moreover, the overexpression of SOX2 is linked to poor differentiation of the tumor cells, lymph node metastasis, and bad prognosis. ${ }^{26,27}$

Studying of cancer stem cell markers in MEC can provide important information about the role of these markers in tumor development and progression. In addition, highlights the targets for future therapy. ${ }^{28}$ No previous studies were done to evaluate the expression of stem cell markers in PSSC.

In the current work, the expression of CD44 and SOX2 in low and high- grades MEC and PSSC was investigated using immunohistochemical staining. 
The aim is to assess the role of cancer stem cells in these neoplasms and to determine whether the expression of these markers can be used to predict tumor aggressiveness. In addition, the possible correlation between both markers was statistically analyzed.

\section{MATERIALS AND METHODS}

A total of sixteen archival paraffin blocks of mucoepidermoid carcinoma (8 low grade and 8 high- grade carcinomas) and sixteen archival paraffin blocks of primary squamous cell carcinoma of salivary glands ( 8 low grade and 8 high- grade carcinomas) were retrieved from:

- The pathological files of General Pathology Department, Nasser Institute for Research and Treatment, Ministry of health and population.

- The pathological files of General Pathology Department, Al Hussein Hospital, Al Azhar University.

\section{Section preparation:}

Three sections from each formalin-fixed, paraffin-embedded tissue block were cut into $4 \mu \mathrm{m}$ thickness and stained with the following:

a) First section stained with hematoxylin and eosin (H\&E) to confirm the diagnosis of mucoepidermoid carcinoma and primary squamous cell carcinoma of salivary glands.

b) Second section stained with CD44 polyclonal antibody.

c) Third section stained with SOX2 monoclonal antibody.

\section{Immunohistochemical (IHC) staining procedure}

The sections were deparaffinized with xylene and rehydrated in graded ethanol for IHC staining with CD44 and SOX2 antibodies. Heat mediated antigen retrieval was done using citrate buffer PH (6.0), then the sections were immersed in hydrogen peroxide ( $\mathrm{H} 2 \mathrm{O} 2)$ to block the endogenous peroxidase activity, washed in phosphate-buffered saline (PBS), and then protein blocking reagent was added and incubated for 20 minutes at $37^{\circ} \mathrm{C}$ within humid chamber to reduce the non-specific staining. The primary antibodies used in the present study were as follows:

- Concentrated polyclonal rabbit antibody for CD44 (Code No. PA5-21419 at dilution 1:100, Thermo Fisher Scientific USA).

- Concentrated monoclonal mouse antibody for SOX2 (Code No. MA1-014 at dilution 1:50, Thermo Fisher Scientific USA).

Sections were incubated with the primary antibody overnight.

The sections were then washed twice in PBS and treated with the labeled streptavidin- biotin complex (LSAB + System-HRP, Dako) at room temperature to bind the primary antibodies. Peroxidase activity was visualized by immersing the tissue sections in diaminobenzidine (Liquid DAB+ Substrate, Dako), which resulted in a brown reaction product. Finally, the sections were counterstained with Mayer's hematoxylin and cover-slipped.

\section{Immunohistochemical Interpretation:}

The immunoexpression of CD44 was evaluated by the presence of brown colored immunostaining reaction in the cell membrane of tumor cells.

Presence of brown colored immunostaining reaction in the nucleus of malignant cells was considered a positive reaction for SOX2.

In each slide, 5 microscopic fields showing the highest immunopositivity were selected and photomicrographed using image analyzer.

Immunoreactivity, for CD44 and SOX2 was assessed by estimating the area percentage of positive immunostained cells in relation to the area examined in each microscopic field using computerized image analyzer (Leica Qwin - Germany) at research unit (Faculty of Dentistry Cairo University). 
The image analyzer consisted of a colored video camera, colored monitor, and hard disk of $h p$ personal computer connected to the microscope and controlled by Leica Qwin 500 software. The image analyzer was calibrated automatically to convert the measurement units (pixels) produced by the image analyzer program into actual micrometer units. The area and area percentage reaction were measured using a magnification x200. Mean values were then obtained for each specimen.

\section{Statistical analysis}

Statistical analysis was then performed using a commercially available software program (SPSS 19; SPSS, Chicago, IL, USA).

As data was parametric, significance of the difference between groups was evaluated using oneway analysis of variance (ANOVA).

Pearson correlation test was used to study correlation between different parameters. The Pearson correlation coefficient is used to measure the strength of a linear association between two variables, where the value $r=1$ means a perfect positive correlation and the value $r=-1$ means a perfect negative correlation.

The level of significance was set at $\mathrm{P}<0.05$.

\section{RESULTS}

\section{1-Heamatoxylin and eosin stain findings}

Histologically Low-grade MECs are characterized by increased cysts formation, minimal cytological atypia and large concentrations of mucous cells while high-grade MECs show a high proportion of squamous and intermediate cells and increased mitotic activity.

PSSC is characterized histologically by sheets and nests of malignant squamous cells which are well differentiated in low-grade tumors and poorly differentiated in high-grade tumors (figure1,A,B, C,D).

\section{2-Immunohistochemical findings}

\section{CD44 immune-reactivity:}

All lesions of MEC and PSSC showed immunopositivity for CD44 in the malignant cells especially in the cell membrane (figure 1, E,F,G, H).

\section{SOX2 immune-reactivity:}

All lesions of MEC and PSSC showed nuclear immunopositivity for $\mathrm{SOX} 2$ in the malignant cells (figure $1, \mathrm{I}, \mathrm{J}, \mathrm{K}, \mathrm{L}$ ).

\section{Results of the immunohistochemical staining:}

\section{Comparison between mucoepidermoid carcinoma and primary squamous cell carcinoma}

Regarding CD44 area percent of immunoexpression, the highest mean value was recorded in MEC high grade, while the lowest value was recorded in MEC low grade, with a statistically significant difference $(\mathrm{p}<0.0001)$. Tukey's post hoc test revealed a statistically significant difference between every 2 groups (Table1, Graph 1 ).

Regarding SOX2 area percent of immunoexpression, a higher mean value was recorded in PSCC high grade, followed by MEC high grade, while the lowest value was recorded in PSCC low grade, with a statistically significant difference $(\mathrm{p}<0.0001)$. Tukey's post hoc test revealed no significant difference between MEC high grade and PSCC high grade. Moreover, there was no significant difference between MEC low grade and PSCC low grade (Table1, Graph 1). 

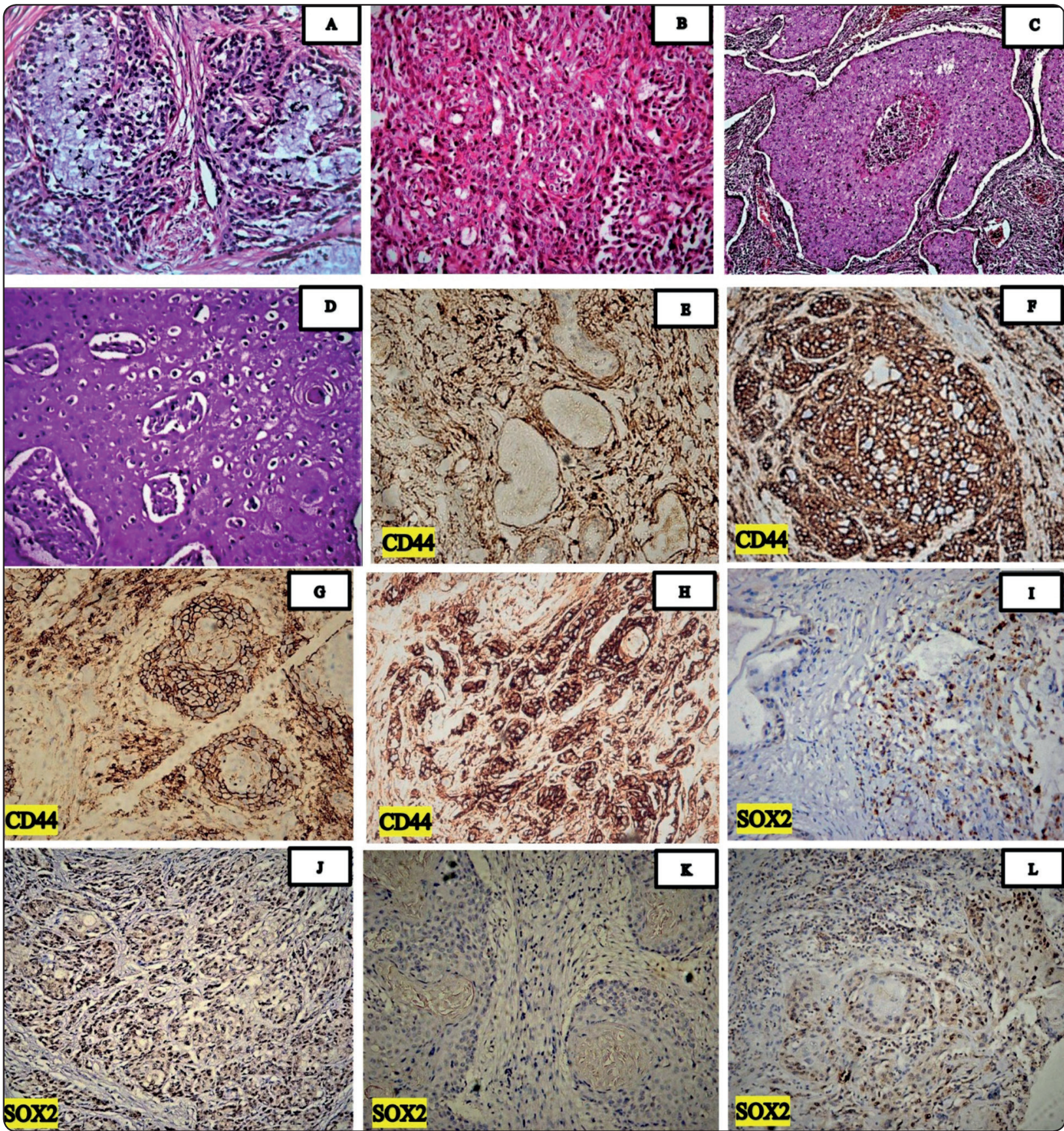

Fig. (1) (A): A photomicrograph of low- grade MEC showing cysts formation, minimal cytological atypia and large concentrations of mucous cells (H\&E x200).

(B): A photomicrograph of high- grade MEC showing squamous and intermediate cells and increased mitotic activity (H\&E x200).

(C): A photomicrograph of low- grade PSSC showing sheets of well differentiated malignant squamous cells (H\&E x100).

(D): A photomicrograph of high- grade PSSC showing sheets of poorly differentiated malignant squamous cells (H\&E x200).

(E): A photomicrograph of low- grade MEC showing immunopositivity for CD44 in the malignant cells (CD44 x 100).

(F): A photomicrograph of high- grade MEC showing immunopositivity for CD44 in the malignant cells (CD44 x 100).

(G): A photomicrograph of low-grade PSSC showing immunopositivity for CD44 in the malignant cells (CD44 x100).

(H): A photomicrograph of high- grade PSSC showing immunopositivity for CD44 in the malignant cells (CD44 x100).

(I): A photomicrograph of low- grade MEC showing immunopositivity for SOX2 in the malignant cells (SOX2 x200).

(J): A photomicrograph of high- grade MEC showing immunopositivity for SOX2 in the malignant cells (SOX2 x 100).

(K): A photomicrograph of low- grade PSSC showing immunopositivity for SOX2 in the malignant cells (SOX2 x100).

(L): A photomicrograph of high grade PSSC showing immunopositivity for SOX2 in the malignant cells (SOX2 x100). 
TABLE (1) Comparison between MEC and PSCC (ANOVA test)

\begin{tabular}{|c|c|c|c|c|c|c|c|c|}
\hline & \multicolumn{4}{|c|}{ SOX2 Area percent } & \multicolumn{4}{|c|}{ CD44 Area percent } \\
\hline & $\begin{array}{c}\text { MEC } \\
\text { (low grade) }\end{array}$ & $\begin{array}{c}\text { MEC } \\
\text { (high grade) }\end{array}$ & $\begin{array}{l}\text { PSCC (low } \\
\text { grade) }\end{array}$ & $\begin{array}{c}\text { PSCC } \\
\text { (high grade) }\end{array}$ & $\begin{array}{c}\text { MEC } \\
\text { (low grade) }\end{array}$ & $\begin{array}{c}\text { MEC } \\
\text { (high grade) }\end{array}$ & $\begin{array}{c}\text { PSCC (low } \\
\text { grade) }\end{array}$ & $\begin{array}{c}\text { PSCC (high } \\
\text { grade) }\end{array}$ \\
\hline Mean & $2.449^{\mathrm{b}}$ & $14.783^{\mathrm{a}}$ & $2.205^{\mathrm{b}}$ & $15.486^{\mathrm{a}}$ & $15.99^{\mathrm{d}}$ & $61.523^{\mathrm{a}}$ & $21.159^{\mathrm{c}}$ & $54.937^{\mathrm{b}}$ \\
\hline Std Dev & 0.749 & 4.255 & 0.828 & 5.344 & 4.569 & 5.764 & 3.228 & 3.663 \\
\hline $\operatorname{Max}$ & 3.604 & 20.918 & 3.213 & 21.181 & 22.694 & 69.351 & 24.46 & 61.225 \\
\hline Min & 1.556 & 8.902 & 1.319 & 9.469 & 11.739 & 54.658 & 17.592 & 52.18 \\
\hline $\mathrm{F}$ & \multicolumn{4}{|c|}{45.769} & \multicolumn{4}{|c|}{237.08} \\
\hline$P$ value & \multicolumn{4}{|c|}{$\mathrm{p}<0.0001 *$} & \multicolumn{4}{|c|}{$\mathrm{p}<0.0001 *$} \\
\hline
\end{tabular}

Significance level $p<0.05$, *significant

Tukey's post hoc test: means sharing the same superscript letter are not significantly different

\section{2- Correlation between expression of CD44 and SOX2}

Pearson's correlation test revealed a strong positive correlation between SOX2 and CD44 area percent of immunoexpression (Table 2, Graph 2).

TABLE (2) Correlation between SOX2 and CD44 area percent of immunoexpression

\begin{tabular}{|l|l|l|l|}
\hline $\mathrm{R}$ & $\mathrm{R}^{2}$ & Interpretation & P value \\
\hline 0.8393 & 0.7044 & strong positive & $0.0024 *$ (significant) \\
\hline
\end{tabular}

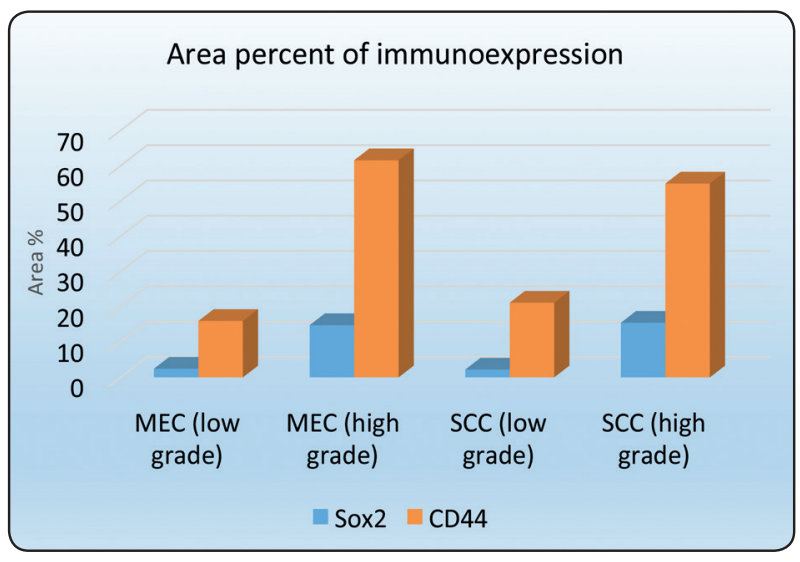

Graph (1) Column chart showing mean SOX2 and CD44 area percent of immunoexpression in Mucoepidermoid carcinoma and Squamous cell carcinoma

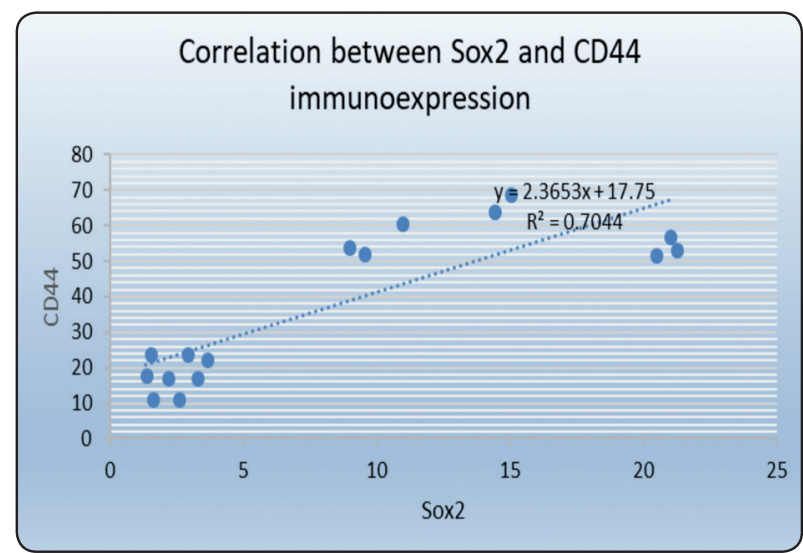

Graph (2) Scatter plot showing correlation between SOX2 and CD44 area percent of immunoexpression 


\section{DISCUSSION}

Salivary gland malignancies often show distant metastases several years after initial diagnosis, suggesting a subpopulation of cancer stem cells (CSCs) responsible for the late recurrences; however, the available models to characterize these rare cells are still limited. ${ }^{29}$

In general, in salivary gland tumors; the hypothesis of cancer stem cell has not been fully examined..$^{30}$

Studies on other types of cancer revealed that cancer stem cells play a functional role in therapy resistance and tumor recurrence. . $11,32,33,34^{2}$

Some studies indicated that cancer stem cells may play an important role in the pathobiology and prognosis of MEC of the salivary gland. ${ }^{34,35}$ No previous studies had been done to investigate the role of CSCs in PSSC of SGs. However, the role of cancer stem cells in head and neck squamous cell carcinoma (HNSCC) was established and may yield new insights into the evolution of new therapeutic modalities for HNSCC. ${ }^{16}$

So, the present study aims to investigate the role of cancer stem cells in MEC and PSSC of SGs which may affect their progression. The expression of stem cell markers CD44 and SOX2 in low and high-grades MEC and PSSC were evaluated and correlated with histopathological parameters. In addition, the correlation between these two markers was detected to evaluate the possible impact of the combination of these two markers on the prognosis of MEC and PSSC.

The resistance of mucoepidermoid carcinomas to every therapeutic modality compounded with its relentless growth is a major clinical obstacle which may be related to cancer stem cells function. ${ }^{35}$ A similar challenge is present for PSSC which is considered as an aggressive neoplasm with an unpredictable response to different therapeutic modalities. Despite adequate therapy, the 5-year survival rate of PSSC remains nearly 25-30\%. However, further studies are needed to understand the pathobiology of PSSC. ${ }^{36,37,38}$

CD44 is an adhesion molecule which is expressed in normal and tumor tissues. ${ }^{4}$ It is considered as a CSC marker which affords high malignant properties and therapeutic resistance. ${ }^{39}$ An important function of CD44 in cancer is the protection of malignant cells from apoptosis through regulation of antiapoptotic or per-apoptotic processes. ${ }^{40,41}$

Overexpressed CD44 was found to be significantly correlated with worse prognosis and malignant clinicopathological features in many types of

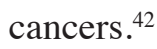

In the current work, immunohistochemical analysis showed expression of CD44 in all cases of MEC and PSSC mainly in the cellular membrane.

Regarding CD44 area percent of immunoexpression, the highest mean value was recorded in MEC high grade followed by PSSC high grade, while the lowest value was recorded in MEC low grade, with a statistically significant difference.

Similarly, previous studies supported the results of the current work and demonstrated expression of CD44 in MEC with intense expression in solid histological type. This expression was higher in the invasive front of the tumor than in the central parts which indicates that CD44 may have a role in MEC progression. . $^{428,35,43,44}$

Previously, Adams et al.$^{35}$ and Warner et al. ${ }^{45}$ reported that mucoepidermoid carcinoma comprised a small cancer stem cells population with increased carcinogenic potential. These cancer stem cells strongly expressed CD44. Their results indicated that therapies that destroy these carcinogenic cells could be of great benefit to MEC patients.

No available data for previous studies concerning the expression of CD44 in PSSC of SG but previous studies were done on HNSCC and are consistent with the present work. 
A study by Joshua et al. ${ }^{42}$ on HNSCC revealed expression of CD44 in all the tested samples. Furthermore, CD44 was found to play an essential role in resistance to chemotherapy and radiotherapy and may be involved in recurrence of head and neck squamous cell carcinomas. ${ }^{46}$ In addition, its expression is positively correlated with metastasis, advanced $\mathrm{T}$ stage, perineural invasion, and shorter disease-free survival. ${ }^{47,48}$

SOX2 is a cancer stem cell marker that has an important role in embryonic development. ${ }^{49}$ Furthermore, it has been linked to carcinogenesis as it can reprogram the differentiated somatic cells into a state similar to pluripotent stem cells..$^{35,50,51}$ This stemness may be responsible for the development and progression of tumors as it allows the ability to differentiation and self-renewal. ${ }^{52}$

So, previous studies suggested an association between SOX2 and tumorigenesis and correlate its expression with aggressive features in different types of malignancies. ${ }^{53-55}$

Regarding salivary gland cancer, the assessment of the expression of SOX2 and other stem cell markers needs further investigations..$^{20}$

In the present study, nuclear expression of SOX2 was detected in all samples of MEC and PSSC. SOX2 area percent of immunoexpression, revealed a higher mean value in PSCC high grade, followed by MEC high grade, while the lowest value was recorded in PSCC low grade, with a statistically significant difference between high grade and lowgrade samples of both tumors. On the other hand, no statistically significant difference between SOX2 expression in MEC and PSSC.

The study of $\mathrm{Xu}$ et $\mathrm{al} .^{30}$ is the only available study concerning SOX2 expression in MEC. They concluded that a high prognostic achievement for palatal MEC could be established through a combination of CD44, CD133 and SOX2 markers.

Findings similar to the present work were observed in adenoid cystic carcinoma (ACC).
In the study of Dai et al. ${ }^{56} \mathrm{SOX} 2$ expression was associated with ACC development. They found a significant correlation between advanced $\mathrm{T}$ stage, distant metastasis and SOX2 expression advocating a clinical relevance of SOX 2 expression to the progression of ACC. In addition, increased expression of SOX2 might be considered as one of the most essential prognostic factors and may represent a target for therapy in ACC.

In carcinoma ex- pleomorphic adenoma (CXPA) SOX2 seems to have a certain role in cancer development and maintenance of the infiltrative growth pattern most probably by adding CSC features to the neoplastic cells. Adding to this, increased SOX2 expression was correlated with increased mitotic activity, high histological grade and poor prognosis in this neoplasm. ${ }^{20}$

Previous studies on various types of tumors as lung cancer $^{57}$, hepatocellular carcinoma ${ }^{58}$, gastric cancer ${ }^{59}$, colorectal cancer ${ }^{53}$, and laryngeal squamous cell carcinoma ${ }^{26}$ demonstrated a correlation between the level of SOX2 expression and the progression and poor prognosis of tumors. Moreover, in breast cancer, SOX2 appears to be involved in chemotherapeutic resistance..$^{60,61}$

In an experimental study, overexpression of SOX2 was reported to facilitate pancreatic cancer cells invasion and metastasis by promoting epithelial-mesenchymal transition. ${ }^{62}$

No available data for previous studies concerning the expression of SOX2 in PSSC of SG. Though overexpression of SOX2 protein may have an important role in initiation and progression in other types of squamous cell carcinomas. ${ }^{63}$

The above data was in accordance with the present results of SOX2 expression in PSSC of SG. So, the present results suggested that the level of SOX2 expression is correlated with MEC and PSSC progression and hence a poor prognosis.

Additionally, the current work detected a strong positive correlation between SOX2 and CD44 area 
percent of immunoexpression. In line, the study of $\mathrm{Xu}$ et al ${ }^{30}$ revealed that the combination of CD44, CD133 and SOX2 is a powerful prognostic indicator for MEC patients.

Likewise, previous studies demonstrated a relation between SOX2 and CD44 expression. They identified a subpopulation of cancer stem cells that overexpress the two markers in HNSSC and concluded that SOX2 and CD44 are essential for the maintenance of the CSCs quiescence and selfrenewal. ${ }^{64,65}$

Though, the results of the current work suggest that SOX2 and CD44 expression may be a useful indicator for the prognosis of MEC and PSCC of the SGs.

Collectively, in this work, the expression of SOX2 and CD44 was linked to the histopathological prognostic parameters in MEC and PSSC. Adding to this, the combination of these two markers could serve as an effective prognostic indicator.

\section{CONCLUSION}

Salivary gland MEC and PSSC exhibit a subpopulation of cancer stem cells. These cells can be detected by SOX2 and CD44 expression and may play an important role in tumoraggressiveness. These results also suggest that MEC and PSSC patients may get benefits from the therapeutic targeting of this cancer stem cells using a combination of the two markers. Nevertheless, the significance of these markers in the diagnosis and prognosis of MEC and PSSC requires further investigation.

\section{REFERRENCES}

1. Guzzo M, Locati LD, Prott FJ, Gatta G, McGurk M, Licitra L. Major and minor salivary gland tumors. Crit Rev Oncol Hematol. 2010; 74:134-148.

2. Seethala RR. An update on grading of salivary gland carcinomas. Head Neck Pathol. 2009; 3:69-77.

3. Bell D, Hanna EY. Salivary gland cancers: biology and molecular targets for therapy. Curr Oncol Rep 2012; 14:166-174.
4. Binmadi N, Elsissi A, Elsissi N. Expression of cell adhesion molecule CD44 in mucoepidermoid carcinoma and its association with the tumor behavior. Head \& Face Medicine. 2016; 12:8.

5. Boukheris H, Curtis RE, Land CE, Dores GM. Incidence of Carcinoma of the Major Salivary Glands According to the WHO Classification, 1992 to 2006: A Population-Based Study in the United States. Cancer Epidemiol Biomarkers Prev 2009;18:2899-906.

6. Barnes L, Eveson JW, Reichart P, Sidransky D. Pathology and genetics of head and neck tumours: IARC Press Lyon, 2005 , pp 245.

7. Elloumi-Jellouli A, Derbel F, Jellouli M, Ben Ammar S, Mrad K, Ben Romdhane Kh. Primary epidermoid carcinoma of the submandibular salivary gland. Dermatol Online J 2005; 11:26.

8. Lewis JE, Olsen KD. Squamous cell carcinoma. In: Barnes L, Eveson JW, Reichart P, Sidransky D, eds. World Health Organization classification of tumours. Pathology and genetics of head and neck tumours. Lyon: IARC Press, 2005:245-6.

9. Cheuk W, Chan JKC. Salivary gland tumours. In: Fletcher CDM, ed. Diagnostic histopathology of tumours. 2nd edn. Philadelphia: Churchill Livingstone, 2000:287-303.

10. Bell RB, Dierks EJ, Homer L. Management and outcome of patients with malignant salivary gland tumours. J Oral Maxillofac Surg. 2005; 63:917-28.

11. Akhtar K, Ray PS, Sherwani R, et al. Primary squamous cell carcinoma of the parotid gland: a rare entity. BMJ Case Rep 2013; 2013: bcr2013009467.

12. Cariati M: Evaluating the link between stem cells and breast cancer. Expert Rev Anticancer Ther 2008; 8:13131322.

13. Oliveira L, Jeffrey S, Ribeiro-Silva A: Stem cells in human breast cancer. Histol Histopathol 2010; 25:371-385.

14. Hermann, P. C. et al. Distinct populations of cancer stem cells determine tumor growth and metastatic activity in human pancreatic cancer. Cell Stem Cell 2007; 1:313-323.

15. Zhang, Z., Filho, M. S. \& Nor, J. E. The biology of head and neck cancer stem cells. Oral Oncol 2012; 48:1-9.

16. Han J, Fujisawa T, Husain SR, Puri RK. Identification and characterization of cancer stem cells in human head and neck squamous cell carcinoma. BMC Cancer. 2014; 14:173. 
17. Jackson M, Hassiotou F, Nowak A. Glioblastoma stemlike cells: at the root of tumor recurrence and a therapeutic target. Carcinogenesis 2014; 36: 177-85.

18. Chen J, Zhou J, Lu J, et al. Significance of CD44 expression in head and neck cancer: a systemic review and metaanalysis. BMC Cancer 2014; 14: 15-15.

19. Cabrera Mc, Hollingsworth Re, Hurt Em. Cancer stem cell plasticity and tumor hierarchy. World J Stem Cells 2015; 7: $27-36$.

20. Sedassari BT, Rodrigues MFSD, Conceição TS, Mariano FV, Alves VAF, Nunes FD, Altemani A, de Sousa SCOM. Increased SOX2 expression in salivary gland carcinoma ex pleomorphic adenoma progression: an association with adverse outcome. Virchows Arch. 2017; 471:775-784.

21. Cao L, Hu X, Zhang J, Liang P, Zhang Y. CD44(+) CD324(-) expression and prognosis in gastric cancer patients. J Surg Oncol 2014; 110:727-33.

22. Ishimoto T, Nagano O, Yae T et al. CD44 variant regulates redox status in cancer cells by stabilizing the $\mathrm{xCT}$ subunit of system xc(-) and thereby promotes tumor growth. Cancer Cell 2011; 19:387-400.

23. Wang L, Zuo X, Xie K, Wei D. The Role of CD44 and Cancer Stem Cells. Methods Mol Biol. 2018; 1692:31-42.

24. Sarkar A, Hochedlinger K. The sox family of transcription factors: versatile regulators of stem and progenitor cell fate. Cell Stem Cell. 2013; 12:15-30.

25. Ellis P, Fagan BM, Magness ST et al. SOX2, a persistent marker for multipotential neural stem cells derived from embryonic stem cells, the embryo or the adult. Dev Neurosci. 2004; 26:148-165.

26. Tang XB, Shen XH, Li L, Zhang YF, Chen GQ. SOX2 overexpression correlates with poor prognosis in laryngeal squamous cell carcinoma. Auris Nasus Larynx. 2013; 40: 481-486.

27. Huang $\mathrm{YH}$, Luo $\mathrm{MH}$, Ni $\mathrm{YB}$ et al. Increased SOX2 expression in less differentiated breast carcinomas and their lymph node metastases. Histopathology. 2014; 64:494-503.

28. Rodrigues MFSD, Sedassari BT, Esteves CM, de Andrade NP et al. Embryonic stem cells markers Oct4 and Nanog correlate with perineural invasion in human salivary gland mucoepidermoid carcinoma. J Oral Pathol Med. 2017; 46: $112-120$

29. Keysar SB, Eagles JR, Miller B, Jackson BC, Chowdhury FN, Reisinger J et al. Salivary gland cancer patient-derived xenografts enable characterization of cancer stem cells and new gene fusions associated with tumor progression. Clin Cancer Res. 2018; 24:2935-2943.

30. Xu, W, Wang Y, Qi X, Xie J, Wei Z, Yin X et al. Prognostic factors of palatal mucoepidermoid carcinoma: a retrospective analysis based on a double-center study. Sci. Rep. 2017; 7:43907.

31. Korkaya H, Paulson A, Charafe-Jauffret E, Ginestier C, Brown M, Dutcher J, Clouthier SG, Wicha MS. Regulation of mammary stem/progenitor cells by PTEN/ Akt/betacatenin signaling. PLoS Biol 2009; 7:e1000121.

32. Hambardzumyan D, Squatrito M, Holland EC. Radiation resistance and stem- like cells in brain tumors. Cancer Cell 2006; 10: 454-456.

33. Shafee N, Smith CR, Wei S, Kim Y, Mills GB, Hortobagyi, Stanbridge EJ, Lee EY. Cancer stem cells contribute to cisplatin resistance in Brca1/p53-mediated mouse mammary tumors. Cancer Res 2008; 68: 3243-3250.

34. Adams A, Warner K, Nör JE. Salivary gland cancer stem cells. Oral Oncol 2013; 49: 845-853.

35. Adams, A. et al. ALDH/CD44 identifies uniquely tumorigenic cancer stem cells in salivary gland mucoepidermoid carcinomas. Oncotarget. 2015; 6: 26633-26650

36. Taxy JB. Squamous carcinoma in a major salivary gland: a review of the diagnostic considerations. Arch Pathol Lab Med. 2001; 125:740-45.

37. Lee S, Kim GE, Park CS, et al. Primary squamous cell carcinoma of the parotid gland. Am J Otolaryngol. 2001; 22:400-6.

38. Panchbhai AS.Primary squamous cell carcinoma of salivary gland: Report of a rare case. J Can Res Ther. 2015; 11:664.

39. Toole, B. P. Hyaluronan-CD44 Interactions in Cancer: Paradoxes and Possibilities. Clinical cancer research: an official journal of the American Association for Cancer Research. 2009: 15: 7462-7468.

40. Park YS, Huh JW, Lee JH, Kim HR. shRNA against CD44 inhibits cell proliferation, invasion and migration, and promotes apoptosis of colon carcinoma cells. Oncol Rep. 2012;27(2):339-346.

41. Chen C, Zhao S, Karnad A, Freeman JW. The biology and role of CD44 in cancer progression: therapeutic implications. Journal of Hematology \& Oncology. 2018; 11:64.

42. Joshua B, Kaplan MJ, Doweck I, Pai R, Weissman IL, Prince ME, et al. Frequency of cells expressing CD44, a 
head and neck cancer stem cell marker: correlation with tumor aggressiveness. Head Neck. 2012; 34:42-9

43. Wein RO, McGary CT, Doerr TD, Popat SR, Howard JL, Weigel $\mathrm{J}$ a, et al. Hyaluronan and its receptors in mucoepidermoid carcinoma. Head Neck. 2006; 28:176-81.

44. Soave DF, Oliveira DA Costa JP, da Silveira GG, et al. CD44/CD24 immunophenotypes on clinicopathologic features of salivary glands malignant neoplasms. Diagn Pathol. 2013; 8: 29-29.

45. Warner, K. A. et al. Characterization of tumorigenic cell lines from the recurrence and lymph node metastasis of a human salivary mucoepidermoid carcinoma. Oral Oncol. 2013: 49: 1059-1066.

46. Kokko LL, Hurme S, Maula SM, Alanen K, Grénman R, Kinnunen I, Ventelä S. Significance of site-specific prognosis of cancer stem cell marker CD44 in head and neck squamous-cell carcinoma. Oral Oncol. 2011; 47: 510516.

47. Wang SJ, Wong G, de Heer AM, et al. CD44 variant isoforms in head and neck squamous cell carcinoma progression. Laryngoscope 2009; 119: 1518-30.

48. Clarke MF, Dick JE, Dirks PB, et al. Cancer stem cellsperspectives on current status and future directions: AACR Workshop on cancer stem cells. Cancer Res 2006; 66: 9339-44.

49. Wang,J.etal.A protein interaction network for pluripotency of embryonic stem cells. Nature. 2006; 444:364-368.

50. Liu XF, Yang WT, Xu R et al. Cervical cancer cells with positive Sox2 expression exhibit the properties of cancer stem cells. PLoS One. 2014; 9: e87092.

51. Boumahdi, S. et al. SOX2 controls tumour initiation and cancer stem-cell functions in squamous-cell carcinoma. Nature. 2014; 511, 246-250.

52. Liu K, Lin B, Zhao M, et al. The multiple roles for Sox2 in stem cell maintenance and tumorigenesis. Cell Signal. 2013; 25:1264- 1271 .

53. Neumann J, Bahr F, Horst D, Kriegl L, Engel J, Luque RM, Gerhard M, Kirchner T, Jung A. SOX2 expression correlates with lymph-node metastases and distant spread in right-sided colon cancer. BMC Cancer. 2011; 11: 518.

54. Lengerke, C. et al. Expression of the embryonic stem cell marker SOX2 in early-stage breast carcinoma. BMC Cancer. 2011; 11:42.
55. Du L. et al. Sox 2 nuclear expression is closely associated with poor prognosis in patients with histologically nodenegative oral tongue squamous cell carcinoma. Oral Oncol. 2011; 47:709-713.

56. Dai W, Tan X, Sun C, Zhou Q. High expression of SOX2 is associated with poor prognosis in patients with salivary gland adenoid cystic carcinoma. Int J Mol Sci. 2014; 15:8393-406.

57. Yang F, Gao Y, Geng J, Qu D, Han Q, Qi J, Chen G. Elevated expression of SOX2 and FGFR1 in correlation with poor prognosis in patients with small cell lung cancer. Int. J. Clin. Exp. Pathol. 2013; 6: 2846-2854.

58. Sun C. Sun L, Li Y, Kang X, Zhang S, Liu Y, SOX2 expression predicts poor survival of hepatocellular carcinoma patients and it promotes liver cancer cell invasion by activating Slug. Med. Oncol. 2013; 30: 503.

59. Zhang X, Yu H, Yang Y, Zhu R, Bai J, Peng Z, He Y, Chen L, Chen W, Fang D, et al. SOX2 in gastric carcinoma, but not Hath1, is related to patients' clinicopathological features and prognosis. J. Gastrointest. Surg. 2010; 14: $1220-1226$.

60. Scheel C, Weinberg RA. Cancer stem cells and epithelialmesenchymal transition : concepts and molecular links. Semin Cancer Biol. 2012; 22:396-403.

61. Piva M, Domenici G, Iriondo O et al. Sox 2 promotes tamoxifen resistance in breast cancer cells.EMBOMol Med. 2014; 6:66-79.

62. Herreros-Villanueva M, Zhang JS, Koenig A, et al. SOX2 promotes dedifferentiation and imparts stem cell-like features to pancreatic cancer cells. Oncogene. 2013; 2:e61.

63. Maier S, Wilbertz T, Braun M, Scheble V, Reischl M, Mikut R, et al. SOX2 amplification is a common event in squamous cell carcinomas of different organ sites. Hum Pathol. 2011;42:1078-88.

64. Bourguignon LY, Wong G, Earle C, Chen L. HyaluronanCD44v3 interaction with Oct4-Sox2-Nanog promotes miR-302 expression leading to self-renewal, clonal formation, and cisplatin resistance in cancer stem cells from head and neck squamous cell carcinoma. J Biol Chem. 2012; 287:32800-24.

65. Huang CF, Xu XR, Wu TF, Sun ZJ, Zhang WF. Correlation of ALDH1, CD44, OCT4 and SOX2 in tongue squamous cell carcinoma and their association with disease progression and prognosis. J Oral Pathol Med. 2014; 43:492-8. 